Acta Cryst. (1991). C47, 1703-1705

\title{
Acetogenic Isoquinoline Alkaloids. XXIII.* Structure of the Naphthyl Isoquinoline Alkaloid Dioncophylline A
}

\author{
By Gerhard Bringmann, $\dagger$ Rainer Zagst, Bernd Schöner, Holger Busse and Martin Hemmerling \\ Institute of Organic Chemistry, University of Würzburg, Am Hubland, D-8700 Würzburg, Germany \\ AND Christian BurschKa \\ Institute of Inorganic Chemistry, University of Würzburg, Am Hubland, D-8700 Würzburg, Germany
}

(Received 20 August 1990; accepted 2 January 1991)

\begin{abstract}
R, 3 R, 7 S)$-7-[1-(4,5-Dimethoxy-2-methyl)naphthyl]-8-hydroxy-1,3-dimethyl-1,2,3,4-tetrahydroisoquinoline, $\mathrm{C}_{24} \mathrm{H}_{27} \mathrm{NO}_{3} \cdot \mathrm{CH}_{2} \mathrm{Cl}_{2}, M_{r}=462 \cdot 4$, orthorhombic, $\quad P 2_{1} 2_{1} 2_{1}, \quad a=11.032(2), \quad b=$ $12 \cdot 420(3), c=17 \cdot 080(8) \AA, V=2340 \cdot 3 \AA^{3}, Z=4$, $D_{x}=1.31 \mathrm{Mg} \mathrm{m}^{-3}, \quad \lambda(\mathrm{Mo} K \alpha)=0.71069 \AA, \quad \mu=$ $0.3 \mathrm{~mm}^{-1}, F(000)=976, T=290 \mathrm{~K}$, final $R=0.063$, for 1617 observed reflections. The structure (constitution and relative configuration) is the same as established recently by spectroscopic, chiroptical, synthetic and degradative methods. A semi-empirical energy minimization calculation yields a structure very close to that of the $\mathrm{X}$-ray analysis.
\end{abstract}

Introduction. Dioncophylline A (Bringmann, Rübenacker, Jansen, Scheutzow \& Aké Assi, 1990), previously 'triphyophylline' (Bruneton, Bouquet, Fournet \& Cavé, 1976), is one of the main alkaloids of the West African medicinal plant (Cooper \& Record, 1931) Triphyophyllum peltatum (Dionocophyllaceae). Most recently, it was isolated for the first time from an Ancistrocladaceae species, Ancistrocladus abbreviatus Airy Shaw, along with the corresponding $N$-methyl derivative (Bringmann, Lisch, Reuscher, Aké Assi \& Günther, 1991). Structurally, it belongs to the increasing novel group of naphthyl isoquinoline alkaloids (Bringmann, 1986), biosynthetically intriguing natural products of apparently acetogenic origin. We have recently been able to establish the complete stereostructure of dioncophylline $\mathrm{A}$ as shown in Fig. 1 (Bringmann, Rübenacker, Jansen, Scheutzow \& Aké Assi, 1990; Bringmann, Jansen, Reuscher, Rübenacker, Peters \& von Schnering, 1990), with $(R)$ configurations at $C(1)$ and $\mathrm{C}(3)$, and with $(S)$ configuration at the stereogenic biaryl linkage, thus completing and revising the structure as published earlier (Bruneton, Bouquet, Fournet \& Cavé, 1976). Unambiguous evidence for this structure was obtained from (1) extensive 1- and

* Part XXII: Bringmann, Geuder, Rübenacker \& Zagst (1991). † Author to whom all correspondence should be addressed.
2D NMR experiments (Bringmann, Rübenacker, Jansen, Scheutzow \& Aké Assi, 1990) [constitution and relative configuration at $\mathrm{C}(1)$ versus $\mathrm{C}(3)]$, (2) CD spectroscopy (Bringmann, Rübenacker, Jansen, Scheutzow \& Aké Assi, 1990) [absolute configuration at the axis], (3) total synthesis (Bringmann, Jansen, Reuscher, Rübenacker, Peters \& von Schnering, 1990) [absolute configurations at C(1) and C(3)], (4) a novel atropoisomer-differentiating cyclization reaction, which synthetically links the axis to the stereogenic centres (Bringmann, Jansen \& Busse, 1991) [relative configuration at the axis], and (5) a degradation method recently described (Bringmann, Rübenacker, Jansen, Geuder \& Aké Assi, 1991; Bringmann, Geuder, Rübenacker \& Zagst, 1991) [absolute configurations at $C(1)$ and $C(3)$ ].

As dioncophylline $A$ is the first representative of the Dioncophyllaceae alkaloids to be fully structurally elucidated, an ultimate proof of this structure by an X-ray crystal analysis was desirable.

Many attempts to obtain appropriate crystals of dioncophylline $A$ failed owing to insufficient quality. Although the crystal used showed a strong decrease in intensity with increasing diffraction angle and thus was not perfect, it was possible to measure enough reflections to get a reliable structure solution, which confirms the constitution and the relative configuration of dioncophylline $A$.

Experimental. Platy white crystals of dioncophylline A, crystallized from dichloromethane/ethanol, $0.5 \times$ $0.2 \times 0.1 \mathrm{~mm}$. Enraf-Nonius CAD-4 computercontrolled single-crystal diffractometer, graphite-

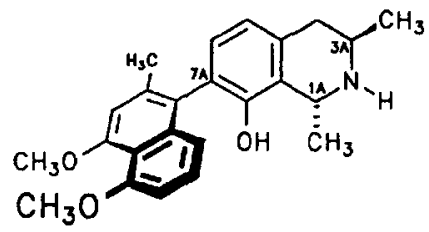

Fig. 1. Structural formula of dioncophylline A. 

speed from $1-4^{\circ} \mathrm{min}^{-1}$, the ratio of peak to background counting time was $2: 1$. Cell parameters from setting angles of 23 reflections having $3 \leq 2 \theta \leq 25^{\circ}$. Data collection at $290 \mathrm{~K}$ : index ranges $-14 \leq h \leq 0$, $-16 \leq k \leq 0,0 \leq l \leq 22$ with $3 \leq 2 \theta \leq 58^{\circ}, 2$ standard reflections $(\overline{2} \overline{6} 4,1 \overline{3} \overline{3})$ measured every $60 \mathrm{~min}$ showed only random deviations from mean intensity, no absorption correction, 3197 reflections measured of which 1617 observed with $F_{o}{ }^{2}>2 \cdot 0 \sigma\left(F_{o}{ }^{2}\right)$.

Structure solved by $S H E L X S 86$ (Sheldrick, 1986). Other programs used were from Nonius $S D P$ package. In the final cycles of least-squares refinement all non- $\mathrm{H}$ atoms anisotropic. All $\mathbf{H}$ atoms calculated $(0.95 \AA), 280$ parameters refined, $\sum w\left(\left|F_{o}\right|-\left|F_{c}\right|\right)^{2}$ minimized with $w=4\left[\left(F_{o}\right)^{2} /\left(\sigma I^{2}+P\left(F_{o}\right)^{2}\right], P=0.04\right.$. $R=0.063, w R=0.061$, max. shift to e.s.d. in the final cycle $=0.03$, goodness of fit $S=0.515, \Delta \rho_{\max }=$ $0.33(6), \Delta \rho_{\min }=-0.26(6)$ e $\AA^{-3}$, scattering factors taken from International Tables for $X$-ray Crystallography (1974, Vol. IV). No abnormal displacement factors were found.

Furthermore, we have calculated the structure of dioncophylline A, using semi-empirical methods (Dewar's AM1 method; Dewar, Zoebisch, Healy \& Stewart, 1985), to give the nearest energy minimized conformation of the molecule, starting from the $\mathrm{X}$-ray data.

Discussion. The title compound crystallizes with one solvent molecule (dichloromethane) per dioncophylline A unit. Final atomic coordinates are reported in Table 1 , interatomic distances and bond angles are presented in Table 2:* Bond lengths, bond angles

- Lists of structure factors, anisotropic thermal parameters, least-squares planes and $\mathrm{H}$-atom parameters have been deposited with the British Library Document Supply Centre as Supplementary Publication No. SUP 53871 (20 pp.). Copies may be obtained through The Technical Editor, International Union of Crystallography, 5 Abbey Square, Chester CHI 2HU, England.

Fig. 2. SCHAKAL86 (Keller, 1988) plot of dioncophylline A. monochromated Mo $K \alpha$ radiation, $\omega / \theta$ scan, scan

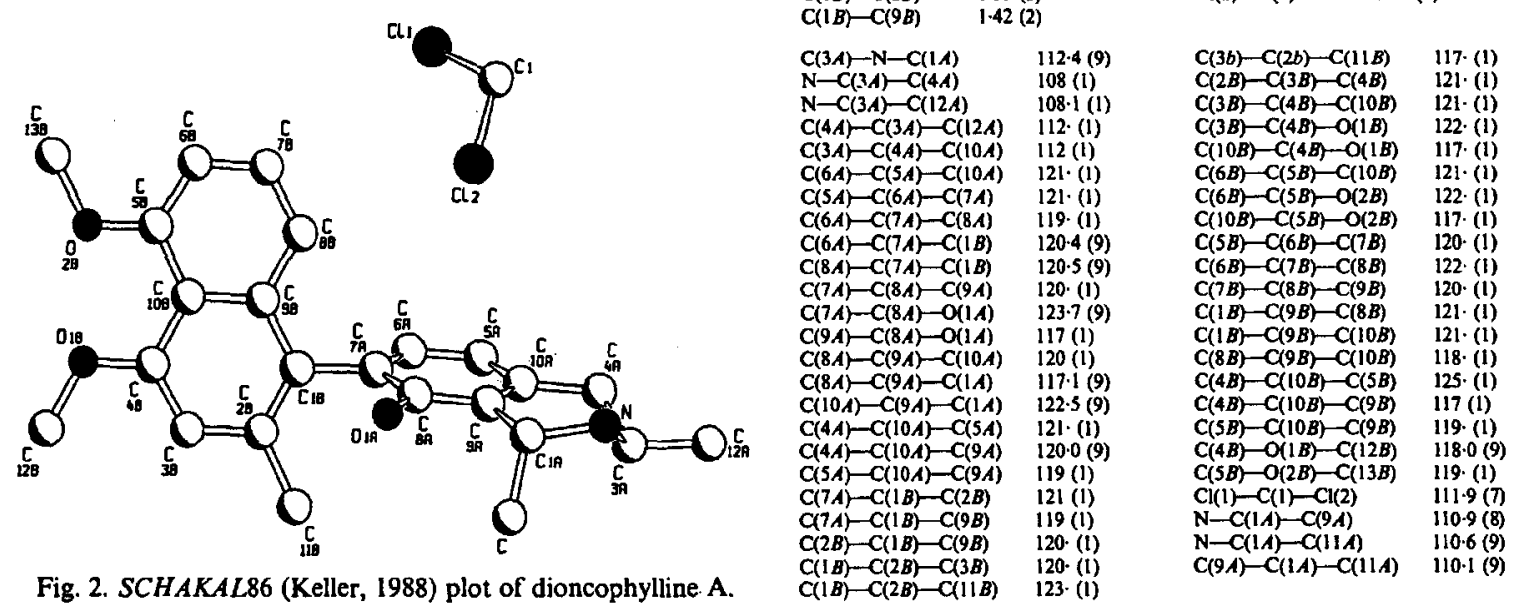

Table 1. Positional parameters and isotropic thermal parameters with e.s.d.'s in parentheses

\begin{tabular}{|c|c|c|c|c|}
\hline & $x$ & $y$ & $z$ & $B_{c q}\left(8 \pi^{2} A^{2}\right)$ \\
\hline $\mathbf{N}$ & 0.2931 (5) & $0.3242(5)$ & 0.0971 (4) & 3.1 (1) \\
\hline $\mathrm{C}(3 A)$ & $0.2467(7)$ & 0.4359 (6) & $0.0964(5)$ & $3.6(2)$ \\
\hline$C(4 A)$ & $0.2464(6)$ & $0.4743(6)$ & $0-0128(4)$ & $3.3(2)$ \\
\hline$C(5 A)$ & 0.4004 (6) & 0.5190 (6) & $-0.0918(5)$ & $3.1(2)$ \\
\hline$C(6 A)$ & 0.5117 (7) & $0.5051(6)$ & -0.1278 (4) & $3.2(2)$ \\
\hline$C(7 A)$ & 0.5932 (7) & 0.4297 (6) & $-0.1013(4)$ & 3.1 (2) \\
\hline$C(8 A)$ & $0.5623(7)$ & $0.3665(6)$ & $-0.0366(4)$ & 3.1 (2) \\
\hline$C(9 A)$ & $0.4501(6)$ & 0.3835 (5) & 0.0014 (4) & 2.5 (1) \\
\hline $\mathrm{C}(10 \mathrm{~A})$ & $0.3690(6)$ & $0.4586(6)$ & $-0.0273(4)$ & 2.7 (1) \\
\hline$C(11 A)$ & $0.5062(7)$ & 0.3566 (7) & $0.1421(5)$ & $4.0(2)$ \\
\hline$C(12 A)$ & 0.1194 (7) & 0.4354 (8) & $0.1315(5)$ & 4.9 (2) \\
\hline$O(1 A)$ & $0.6359(4)$ & $0.2889(4)$ & $-0.0059(3)$ & 3.7 (1) \\
\hline$C(1 B)$ & $0.7192(6)$ & 0.4227 (6) & -0.1370 (4) & $2 \cdot 8$ (1) \\
\hline$C(2 B)$ & 0.8171 (7) & $0.4587(6)$ & $-0.0972(4)$ & 3.2 (2) \\
\hline$C(3 B)$ & $0.9329(6)$ & 0.4576 (6) & $-0.1336(5)$ & 3.4 (2) \\
\hline$C(4 B)$ & $0-9484$ (7) & $0.4198(6)$ & -0.2078 (4) & 3.1 (1) \\
\hline$C(S B)$ & $0.8564(7)$ & 0.3347 (6) & $-0.3285(5)$ & $3.6(2)$ \\
\hline$C(6 B)$ & $0.7550(7)$ & 0.2961 (7) & $-0.3662(5)$ & 4.2 (2) \\
\hline$C(7 B)$ & 0.6429 (8) & 0.3011 (7) & $-0.3296(5)$ & 4.4 (2) \\
\hline$C(8 B)$ & $0.6292(7)$ & $0.3424(6)$ & $-0.2561(4)$ & $3.3(2)$ \\
\hline$C(9 B)$ & 0.7317 (7) & $0.3827(6)$ & $-0.2144(4)$ & $3 \cdot 1$ (1) \\
\hline$C(10 B)$ & 0.8481 (6) & $0.3796(6)$ & $-0.2519(4)$ & 2.9 (1) \\
\hline$C(! 1 B)$ & $0.8110(7)$ & $0.5005(7)$ & $-0.0136(4)$ & 4.5 (2) \\
\hline$C(12 B)$ & $1 \cdot 1588(7)$ & 0.4591 (8) & $-0.2017(5)$ & $5.5(2)$ \\
\hline$C(13 B)$ & 0.9798 (9) & 0.2934 (9) & -0.4397 (5) & 6.4 (3) \\
\hline$O(B)$ & $1.0592(5)$ & 0.4166 (5) & $-0.2429(3)$ & 4.0 (1) \\
\hline$O(2 B)$ & $0.9686(5)$ & $0.3301(5)$ & $-0.3609(3)$ & $4-9$ (1) \\
\hline cl(1) & 0.7003 (3) & $0.7583(3)$ & 0.8678 (2) & $7.98(8)$ \\
\hline cl(2) & 0.6683 (3) & 0.6984 (3) & 0.7065 (2) & 9.4 (1) \\
\hline$C(1)$ & $0.7665(7)$ & $0.7004(8)$ & $0.7861(6)$ & $6.2(3)$ \\
\hline $\mathrm{C}(1 A)$ & $0.4252(6)$ & $0.3177(6)$ & 0.0744 (4) & 3.0 (1) \\
\hline
\end{tabular}

Anisotropically refined atoms are given in form of the isotropic equivalent displacement parameter defined as:

$B_{\mathrm{eq}}=(4 / 3)\left[a^{2} \beta(1,1)+b^{2} \beta(2,2)+c^{2} \beta(3,3)+a b(\cos \gamma) \beta(1,2)+\right.$ $a c(\cos \beta) \beta(1,3)+b c(\cos \alpha) \beta(2,3)]$.

Table 2. Bond distances $(\AA)$ and bond angles $\left(^{\circ}\right)$ with e.s.d.'s in parentheses

$\begin{array}{llll}N-C(3 A) & 1.48(1) & C(2 B)-C(3 B) & 1.42(2) \\ N-C(1 A) & 1.51(1) & C(2 B)-C(11 B) & 1.52(2) \\ C(3 A-C(4 A) & 1.51(2) & C(3 B)-C(4 B) & 1.36(2) \\ C(3 A)-C(12 A) & 1.53(2) & C(4 B)-C(10 B) & 1.43(2) \\ C(4 A)-C(10 A) & 1.53(1) & C(4 B)-O(1 B) & 1.36(1) \\ C(5 A)-C(6 A) & 1.38(1) & C(5 B)-C(6 B) & 1.38(2) \\ C(5 A)-C(10 A) & 1.38(1) & C(5 B)-C(10 B) & 1.42(2) \\ C(6 A)-C(7 A) & 1.37(2) & C(5 B)-O(2 B) & 1.36(1) \\ C(7 A)-C(8 A) & 1.40(1) & C(6 B)-C(7 B) & 1.39(2) \\ C(7 A)-C(1 B) & 1.52(1) & C(7 B)-C(8 B) & 1.37(2) \\ C(8 A)-C(9 A) & 1.41(1) & C(8 B)-C(9 B) & 1.43(2) \\ C(8 A)-O(1 A) & 1.37(1) & C(9 B)-C(10 B) & 1.44(2) \\ C(9 A-C(10 A) & 1.38(1) & C(12 B)-O(1 B) & 1.41(1) \\ C(9 A)-C(1 A) & 1.52(1) & C(13 B)-O(2 B) & 1.43(1) \\ C(11 A)-C(1 A) & 1.54(1) & C(1)-C(1) & 1.73(1) \\ C(1 B)-C(2 B) & 1.35(2) & C(2)-C(1) & 1.74(2) \\ C(1 B-C(9 B) & 1.42(2) & & \end{array}$




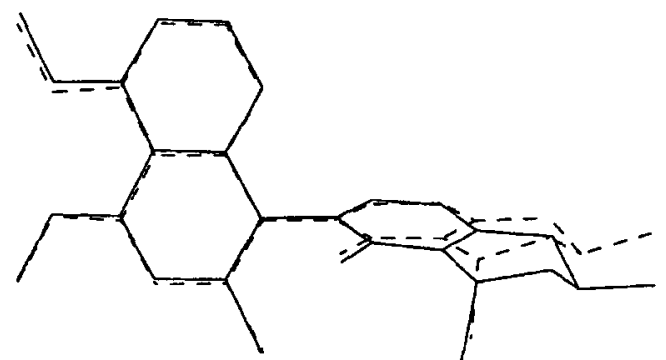

Fig. 3. Superimposed view of dioncophylline A molecules as determined by $\mathrm{X}$-ray diffraction (full lines) and by energy minimization (dashed lines).

and torsion angles of dioncophylline $A$ show no unusual features. The relative configuration at the three stereo-elements (two centres and the axis) is in full agreement with the stereostructure as established earlier (Bringmann, Jansen, Reuscher, Rübenacker, Peters \& von Schnering, 1990). The absolute configuration, as shown in Fig. 2 was not determined here, but was adopted from our work mentioned above. The dihedral angle between the two aromatic parts of the biaryl system is $110 \cdot 2^{\circ}$.

As the AM1 energy minimization calculation (Dewar, Zoebisch, Healy \& Stewart, 1985) shows, the molecule in the crystal is close to one of the local energy minima, and hence there are no greater distortions in the molecule that might arise from intermolecular interactions (Fig. 3).

Financial support of this work by the Deutsche Forschungsgemeinschaft and by the Fonds der
Chemischen Industrie is gratefully acknowledged. Furthermore we wish to thank Professor Dr U. Schubert, Institute of Inorganic Chemistry, Univ. of Würzburg, for enabling us to use the Enraf-Nonius diffractometer.

\section{References}

BRINGMANN, G. (1986). The Naphthyl Isoquinoline Alkaloids In The Alkaloids, Vol. 29, edited by A. Brossl, pp. 141-184. New York: Academic Press.

BringmanN, G., Geuder, T., Rübenacker, M. \& ZaGst, R. (1991). Phytochemistry, 30, 2067-2070.

Bringmann, G., Jansen, J. R. \& Busse, H. (1991). Justus Liebigs Ann. Chem. In the press.

BringmanN, G., JANSEN, J. R., ReusCher, H., RübenaCker, M., Peters, K. \& VON SCHNERING, H. G. (1990). Tetrahedron Lett. 31, 643-646.

BringmaNn, G., Lisch, D., Reuscher, H., Aké Assi, L. \& GÜNTHer, K. (1991). Phytochemistry, 30, 1307-1310.

Bringmann, G., Rübenacker, M., JanSen, J. R., Geuder, T. \& AkE Assi, L. (1991). Planta Med. 56, 495-496.

Bringmann, G., Rübenacker, M., Jansen, J. R., Scheutzow, D. \& AKÉ ASSI, L. (1990). Tetrahedron Lett. 31, 639642 .

Bruneton, J., Bouquet, A., Fournet, A. \& Cavé, A. (1976). Phytochemistry, 15, 817-818

CoOper, G. P. \& Record, S. J. (1931). Bull. Yale Univ. Sch. For. 31, 1-153.

Dewar, M. J. S., Zoebisch, E. G., Healy, E. \& Stewart, J. J. P. (1985). J. Am. Chem. Soc. 107, 3902-3909.

KELLER, E. (1988). SCHAKAL88. A FORTRAN Program for the Graphic Representation of Molecular and Crystallographic Models. Kristallographisches Institut der Universität, D-7800 Freiburg, Germany.

SHELDRICK, G. M. (1986). SHELXS86. Program for the automatic solution of crystal structures. Univ. of Göttingen, Germany.

Acta Cryst. (1991). C47, 1705-1707

\title{
Structure of L-Lysinamide Dihydrochloride. A New Conformation of the Lysine Side Chain
}

\author{
By X. De la Cruz, J. Tormo, I. Fita and J. A. Subirana \\ Departament d'Enginyeria Química, Universitat Politecnica de Catalunya, Diagonal 647, E-08028 Barcelona, \\ Spain
}

(Received 30 April 1990; accepted 21 December 1990)

Abstract. L-Lysinamide dihydrochloride, $\mathrm{C}_{6} \mathrm{H}_{17^{-}}$ $\mathrm{N}_{3} \mathrm{O}^{2+} .2 \mathrm{Cl}^{-}, M_{r}=218 \cdot 14$, monoclinic, $C 2, a=$ $19.998(52), b=4.942(26), c=15.997(32) \AA, \beta=$ $138.04(29)^{\circ}, \quad V=1057 \cdot 1 \AA^{3}, \quad Z=4, \quad D_{x}=$ $1.371 \mathrm{~g} \mathrm{~cm}^{-3}, \lambda($ Mo $K \alpha)=0.71069 \AA, \mu=5.9 \mathrm{~cm}^{-1}$ $F(000)=464$, room temperature, $R=0.067$ for 599 observed reflections. No head-to-tail hydrogen bonds between terminal $\mathbf{N}$ and $\mathbf{C}$ groups are observed in the structure. All suitable $\mathrm{H}$ atoms are involved in at least one hydrogen bond. The lysine side chain conformation $\left(g^{-} t g^{-} t\right)$ has not been previously observed.

Introduction. Amino acid derivatives and small peptide structures contain detailed information which is useful in protein conformation studies. The structure determination of L-lysinamide dihydrochloride is part of a project that involves the struc(C) 1991 International Union of Crystallography 